\title{
Research on the Development of County Finance in Guizhou Province in the
} Promotion of Precise Poverty Alleviation

\author{
Yu Ding Mu Zhang \\ Guizhou University of Finance and Economics, Guiyang 550025 ,China
}

\begin{abstract}
This paper selects the 50 state-level poverty-stricken counties in Guizhou province as the research object, and uses financial scale, financial efficiency and financial structure to represent the level of financial development in each county, using economic growth and income distribution as controlled variable. The poverty of every county is expressed by poor slow index. Applying the panel data model, the promotion of local financial development to the targeted poverty alleviation is studied. The empirical evidence shows that the financial scale, financial efficiency, financial structure, economic growth and poverty reduction of 50 national poverty-stricken counties in Guizhou province are positively correlated. However the financial scale is more significant to reduce the incidence of poverty than that of financial efficiency.
\end{abstract}

\section{Keywords}

Financial development; Precision for poverty alleviation; Panel data model

\section{贵州县域金融发展对精准扶贫的促进作 用研究}

丁豫 张目

贵州财经大学，贵阳 550025, 中国

摘要: 本文选取了贵州省 50 个国家级贫困县作为研究对象, 用金融规模、金融效率、金融结 构来表示各县的金融发展水平，以经济増长和收入分配作为控制变量，每个县的贫困程度用 贫困减缓指标来表示。运用面板数据模型研究当地金融发展对精准扶贫的促进作用。实证表 
明贵州省 50 个国家级贫困县金融规模、金融效率、经济增长与贫困减缓呈正相关关系。而相 比金融效率，金融规模对贫困发生率的降低起到的作用更为显著。

关键词: 金融发展; 精准扶贫; 面板数据模型

\section{1. 引言}

本文所研究的贵州省作为全国贫 困人口最多、贫困面积最大、贫困程度 最深的省，多年来紧跟政策步伐。根据 贵州省统计局最新数据, 贵州省国际级 贫困县仍多达 50 个, 因此脱贫道路任 重道远。2014 年, 习近平总书记提出了 “精准扶贫” 的理念。这个理念成为全 国扶贫工作的基本方略。而金融是具有 配置其他资源功能的资源, 其配置总 量、配置效率直接决定了经济发展水 平。在贵州当前的贫困形势和 “精准扶 贫” 政策下，如何结合金融发展促进扶 贫工作是值得探讨的问题。

\section{2. 文献回顾}

谭伶俐（2011）采用全国 23 个省 $2000-2008$ 年的数据, 建立固定效应向 量分解模型, 研究表明农村金融发展直 接和间接都能显著地缓解贫困,农村金 融发展过程中的不稳定性对贫困的影 响不显著 ${ }^{[1]}$ 。崔艳娟和孙刚（2012）分 别选取金融发展规模、效率作为金融发 展指标,通过实证检验多年中国各省面 板数据得出:金融发展可以通过经济增 长、收入分配途径提高穷人的收入水平, 但金融波动会抵消金融发展的减贫效 果 ${ }^{[2]}$ 。伍艳 (2012) 发现 2001 2010 年
中国农村金融发展与贫困发生率负相 关 ${ }^{[3]}$ 。郭威（2013）认为农村金融扶贫 面临的困境包括:金融机构发展难以满 足资金需求日益扩大,监管标准阻碍金 融机构业务拓展,信用环境差,农户抵押 缺失 ${ }^{[4]}$ 。Song X, Li L 和 Xiao L（2017） 采用信用风险模型对农村信贷问题进 行了分析, 认为信贷风险的不确定加大 了农村户口获取信贷资金的难度，为提 高信贷有效配给，加大金融扶贫力度提 出了合理的建议 [5]。邓坤（2015）对四 川省巴中市 3 县 1 区近 4 年的面板数据 分析,发现涉农贷款占比增加并不能提 高农民收入。另外,从构建的金融扶贫效 率指标来看,农村企业组织贷款的扶贫 效率在样本期内呈上升趋势 ${ }^{[6]}$ 。

金融发展对精准扶贫促进作用研 究的文献不少, 但贵州作为减贫形势严 重的省, 目前的研究却少有对贵州省县 域金融发展对精准扶贫的促进作用研 究。有鉴于此, 本文运用面板数据模型 对 2013 年至 2015 年贵州省 50 个国家 级贫困县金融发展对精准扶贫促进作 用进行研究。

\section{3. 面板数据线性回归模型}

\section{1 面板数据}

面板数据是指固定一组调查对象 
在等间隔时点连续观测得到的数据, 是 具有截面和时间两个特征的数据。面板 数据用双下标量表示, 例如

$$
\text { Yit, } \mathrm{i}=1,2, \cdots, \mathrm{N} ; \mathrm{t}=1,2, \cdots, \mathrm{T}
$$

其中 $\mathrm{i}$ 对应面板数据中不同个体, $\mathrm{N}$ 表示面板数据种的个体数。 $\mathrm{t}$ 对于面 板数据中不同的时点, $\mathrm{T}$ 表示时间序列 的最大长度。若固定 $\mathrm{t}$ 不变, Yi.,

$(i=1,2, \cdots, N)$ 是横截面上的 $\mathrm{N}$ 个随机 变量; 若固定 $\mathrm{i}$ 不变, Y.t, $(\mathrm{t}=1,2, \cdots, \mathrm{T})$ 是纵剖面上的一个时间序列。面板数据 分为两种特征。一是截面上个体数少, 而每个个体的时间跨度长。二是截面上 个体数多, 而每个个体时间跨度短。

\section{2 面板数据模型}

基于面板数据的回归模型称为面 板数据模型，通常区分线性和非线性等 类型为了方便，本文就称线性面板数据 回归模型为面板数据模型面板数据模 型的一般形式为

$$
\mathrm{Y}_{i t}=\alpha_{i t}^{*}+\sum_{h=1}^{K} \beta_{h i t} x_{h i t}+u_{i t}, i=1,2, \ldots, \mathrm{N} ; \mathrm{t}=1,2, . ., \mathrm{T}
$$

其中, $\mathrm{Y}_{\mathrm{it}}$ 是被解释变量对于个体 $\mathrm{i}$ 在 $\mathrm{t}$ 时的观测值, $x_{\text {hit }}$ 为第 $\mathrm{h}$ 个解释变量 对于个体 $\mathrm{i}$ 在 $\mathrm{t}$ 时的观测值; $\beta_{\text {hit }}$ 为第 $\mathrm{h}$ 个解释变量的待估参数; $u_{i t}$ 是随机误差 项。面板模型通常分为三类, 即混合模 型、固定效应模型和随机效应模型。

\section{4. 实证分析}

\section{1 模型、指标与数据}

\subsection{1 模型的设定}

本文旨在研究金融发展对精准扶
贫的促进作用，选取一些具有代表性的 指标来表示贵州金融发展水平，而每个 县的贫困程度则用贫困减缓指标来表 示。基于金融发展对经济增长有着正向 促进作用的假设, 主要通过经济增长和 收入分配两个渠道影响贫困的减缓。故 本文选取 3 个因素来作为实证方程的自 变量, 分别为金融发展水平、经济増长、 收入分配。其中, 我们将金融发展水平 从金融规模、金融效率和金融结构三方 面来衡量。此外, 还有很多因素可减缓 贫困，例如政府部口的投资、居民受教 育程度等, 这些影响因素我们统一用随 机误差项来表示。得到以下基本模型: $P O V_{i t}=C_{i}+\alpha F S_{i t}+\beta F E_{i t}+\eta F S R_{i t}+\gamma R G P_{i t}+\delta I G_{i t}+\mu_{i t}$

其中, POV 表示贫困程度, FS 表 示金融规模, FE 表示金融效率, FSR 表示金融结构, RGP 表示经济増长, IG 表示收入分配， $\mu$ 表示影响贫困减缓的 其他因素， $i=1 ， 2 ， 3 \cdots 50$ ，表示贵州 省 50 个扶贫开发重点具; $\mathrm{t}=1,2,3$, 表示不同年份。

\subsection{2 指标的选取}

贫困减缓指标（POV）：本文采用 贫困发生率来衡量贫困的程度。该指标 的数值越大, 贫困情况越严重。

金融规模指标（FS）：借鉴崔艳娟 （2012） ${ }^{[7]}$ 的做法, 采用存贷款总额 / GDP 来作为金融规模的指标。该指标的 数值越大，表明金融体系发展规模越 大，金融发展水平越高。

金融结构指标（FSR）：代表经济 体中产业资本的存在结构，是衡量金融 结构的重要指标, 它等于直接融资额比 
间接融资额。根据贵州省县域的直接情 况，股票融资是企业融资的主要方式， 债券等其他融资方式发展还不完善, 再 次忽略不计。又因为贵州省全省共计上 市公司 26 家，其中只有 2 家位于国家 级贫困县名单中, 因此本文采用 0-1 规 划对变量进行处理, 拥有上市公司的县 取值为 “ 1 ”，其余取值为 “ 0 ”。

金融效率指标（FE）：运用全社会 固定资产投资额与银行业金融机构各 项存款余额计算得到。该指标数值越 大，说明金融机构用于投资的效率越 高，金融效率就越高。

经济増长指标（RGP）：衡量经济 增长的指标有很多。本文采用人均 GDP 来衡量经济的增长, 该指标若成上升趋 势, 说明经济增长、发展良好。

收入分配指标（IG）：考虑到数据 的可比性和联系性, 故采用城镇人均可 支配收入/农村人均纯收入来衡量收入 分配的平等情况。该指标的数值上升, 说明城乡居民的收入差距越来越大, 收 入分配越不公平。

\subsection{3 数据来源及说明}

根据贵州最新统计年鉴，贵州省共 有 50 个国家级贫困县。本文收集了 2013 年至 2015 年 50 个国家级贫困县数据, 统计口径一致, 所选取数据可信度高。 数据主要来源于 2013 年至 2015 年《贵 州统计年鉴》，部分数据用 excel 表格 进行简单处理所得。

\section{2 实证检验过程}

\subsection{1 固定效应模型检验}

贫困发生率作为因变量会受到模 型中的自变量:金融规模、金融效率、金 融结构、经济增长和收入分配的影响, 还会受到其他一些与特定观察对象或 时期存在联系的因素的影响。固定效应 模型, 将这些其他因素的综合影响效果 看作是固定不变的, 在一定程度上提高 了对实际数据的拟合度。贵州省 50 个 扶贫开发重点县, 是相对独立的个体又 是统一的主体, 为了体现出整体中个体 的差异, 本文先采用固定效应变截距模 型，回归结果见表 4-2.

表 4-2 固定效应模型回归结果

\begin{tabular}{|c|c|c|c|}
\hline 贫困减缓指标 & 参数估计值 & 标准误差 & $\mathrm{P}>\mathrm{t}$ \\
\hline 金融规模 & -0.05774 & 0.0110099 & 0 \\
\hline 金融效率 & -0.01377 & 0.0074121 & 0.06 \\
\hline 金融结构 & omitted & & \\
\hline 经济增长 & -0.11729 & 0.0063662 & 0 \\
\hline 收入分配 & 0.02139 & 0.0139213 & 0.12 \\
\hline 常数 C & 0.51337 & 0.0616472 & 0 \\
\hline
\end{tabular}

由表 4-2 可见金融结构在结果中出 现 omitted, 表示变量出现多重共线性, 因此从模型中删除该变量。本人认为金 融结构出现多重共线性的主要原因是 由于金融结构用上市公司计算这一指 标，而贵州省 50 个国家级贫困县中上 市公司数量太少，导致数据不理想，最 后不得不删除金融结构这一指标。 


\subsection{2 删除共线性变量后}

(1) Hausman 检验

将原始数据中删除金融结构 (FSR) 解释变量, 利用 Stata11.0 软件进行 Hausman 检验, 结果见表 4-3。

表 4-3 删除共线性变量后的 Hausman 检验结果

\begin{tabular}{|c|c|}
\hline \multicolumn{2}{|c|}{ Hausman 检验 } \\
\hline Chi $(0)=0.00$ & Prob $>$ chi $2=0.00$ \\
\hline
\end{tabular}

由于 $\mathrm{P}$ 值为 0.00 , 故强烈拒绝原假 设, 应运用固定效应模型估计更合适。

（2）固定效应模型回归结果

从原始数据中删除金融结构后，利 用 Stata11.0 软件进行参数估计, 结果如 表 4-4 所示。

表 4-4 删除共线性变量后固定效应模型回归结果

\begin{tabular}{|c|c|c|c|}
\hline 贫困减缓指标 & 参数估计值 & 标准差 & $\mathrm{P}>\mathrm{t}$ \\
\hline 金融规模 & -0.05830 & 0.01101 & 0 \\
\hline 金融效率 & -0.01388 & 0.00742 & 0.064 \\
\hline 经济增长 & -0.11753 & 0.00637 & 0 \\
\hline 收入分配 & 0.02141 & 0.01394 & 0.128 \\
\hline 常数 C & 0.51502 & 0.06168 & 0 \\
\hline
\end{tabular}

从表 4-4 可知, 金融规模、金融效 率、经济增长指标对贵州贫困县的贫困 发生率负相关, 说明此三项指标可减缓 贵州国家级贫困县的贫困发展, 这与现 实经济意义相符。收入分配差距越大, 贵州省国家级贫困县的贫困发生率越 高, 两者呈正相关。金融规模、金融效 率、经济增长指标的 $\mathrm{P}$ 值均小于 0.05 , 所以其在 $95 \%$ 置信度下均显著, 而收入 分配的 $\mathrm{P}$ 值为 0.128 , 表明在 $12.8 \%$ 的情 况下收入分配与贵州省国家级贫困县
的减缓情况没有影响，没有通过显著性 检验。所以, 从模型中删除该不显著项。 收入分配对贫困减缓不显著的原因主 要是, 收入分配指标采用城镇人均可支 配收入/农村人均纯收入所得, 收入分配 不应只考虑城镇收入与农村收入之间 的分配, 还应考虑工业投放等因素。

\subsection{3 删除不显著项后}

(1) Hausman 检验

将原始数据中删除收入分配（IG） 这一控制变量, 利用 Stata11.0 软件进行 Hausman 检验, 结果见表 4-5。

表 4-5 删除不显著项后 Hausman 检验结果

\begin{tabular}{|c|c|}
\hline \multicolumn{2}{|c|}{ Hausman 检验 } \\
\hline Chi $(0)=0.00$ & Prob $>$ chi $2=0.00$ \\
\hline
\end{tabular}

（2）固定效应模型回归结果

根据 2013 年-2015 年贵州省 50 个 国家级贫困县原始数据, 删除收入分配 后, 利用 Stata11.0 软件进行参数估计, 得出如表 4-6 所示结果。

表 4-6 删除共线性变量后固定效应模型回归结果

\begin{tabular}{|c|c|c|c|}
\hline 贫困减缓指标 & 估计参数 & 标准差 & $\mathrm{P}>\mathrm{t}$ \\
\hline 金融规模 & -0.05769 & 0.011084 & 0 \\
\hline 金融效率 & -0.01582 & 0.007365 & 0.03 \\
\hline 经济增长 & -0.12475 & 0.004328 & 0 \\
\hline 常数 C & 0.60159 & 0.025240 & 0 \\
\hline
\end{tabular}

从表 4-6 可知, 回归结果中指标均 显著，且金融发展规模对贵州省国家级 贫困县的减缓作用最为显著, 从而得到 回归方程:

$P O V_{i t}=0.60159-0.05769 F S_{i t}-0.01582 F E_{i t}-0.12475 R G P_{i t}+\mu_{i t}$ 


\section{3 实证检验结果分析}

从实证结果来看, 贵州省国家级贫 困县金融规模、金融效率、经济增长与 贫困减缓呈正相关关系。扩大金融规 模、提高金融效率、促进经济的增长都 将降低贫困发生率，能有效缓解贫困。

从回归方程金融规模和金融效率 的回归系数来看: 金融规模相对于金融 效率来说, 对贫困发生率的降低起到的 作用更为显著。金融效率的提高, 能够 给居民提供更多的储信贷支持服务，而 金融发展规模的扩大更多意味着金融 机构数量和金融总量的扩大, 从而对贫 困的缓解起到有效作用。

贵州省国家级贫困县金融发展对 贫困缓解起到正向有效的作用。金融发 展除直接作用贫困减缓外, 还通过经济 増长的间接作用对贫困缓解发挥作用。

\section{5. 结论与讨论}

目前虽然有许多文献研究了金融 与扶贫的关系, 但是针对贵州县域的研 究本文具有独创性。本文研究结果表明 贵州省 50 个国家级贫困县金融规模、 金融效率、经济增长与贫困减缓呈正相 关关系。其中金融规模相对于金融效率 来说, 对贫困发生率的降低起到的作用 更为显著。因此特惠金融可以通过提高 其发展规模, 增加金融机构数量和相关 金融从业人员。除此之外, 经济发展对 减贫有重要作用, 当地政府应大力发展 当地经济, 减贫效果将会大有提升。文
中原本选取的控制变量收入分配采取 城镇人均可支配收入/农村人均纯收入 所得, 但最后导致结果不显著。若是能 用基尼系数来表示每个县的收入分配 指标也许会更好。但由于数据无法获 得, 因此无法计算基尼系数, 是本文的 一大遗憾, 也希望在之后的研究中可以 继续改善和完善这一缺憾。

\section{参考文献}

[1] 谭伶俐. 农村金融与贫困 [D].吉林 大学, 2011 .

[2] 崔艳娟,孙刚. 金融发展是贫困减缓 的原因吗?-—来自中国的证据 $[\mathrm{J}]$. 金融研究,2012,(11):116-127.

[3] 伍艳. 中国农村金融发展的减贫效 应研究一一基于全国和分区域的分 析 $[\mathrm{J}]$. 西南民族大学学报(人文社会 科学版),2012,33(07):109-113.

[4] 郭威. 农村金融扶贫的经验、困境 与对策一一以广西富川县为例 $[\mathrm{J}]$. 理论探索,2013,(05):98-102.

[5] Song X, Li L, Xiao L. Review of Research on Credit Risk Management for Rural Credit Cooperatives[J]. Journal of Risk Analysis \& Crisis Response, 2017, 7(1):21.

[6] 邓坤. 金融扶贫惠农效率评估一一 以秦巴山区巴中市为例 [J]. 农村经 济,2015,(05):86-91.

[7] 崔艳娟. 我国金融发展对贫困减缓 的影响: 理论与实证 [D].东北财经大 学,2012. 